\title{
Interactions of amphiphiles with plasticisers used in polymers: Understanding the basis of health and environmental challenges ${ }^{2}$
}

\author{
Emil Gustafsson ${ }^{\mathrm{a}}$, Tim Melander Bowden ${ }^{\mathrm{a}}$, Adrian R. Rennie ${ }^{\mathrm{b}, *}$ \\ a Polymer Chemistry, Department of Chemistry - Ångström, Uppsala University, Box 538, 75121 Uppsala, Sweden \\ ${ }^{b}$ Centre for Neutron Scattering, Uppsala University, Box 516, 75120 Uppsala, Sweden
}

\section{A R T I C L E I N F O}

Article history:

18 January 2020

Available online 21 January 2020

\section{Keywords:}

Polyvinyl chloride

Plasticiser

Surfactant

Phthalate esters

Solubility

\begin{abstract}
A B S T R A C T
Plasticisers are widely used to provide desirable mechanical properties of many polymeric materials. These small molecule additives are also known to leach from the finished products, and this not only may modify the physical properties but the distribution of these materials in the environment and in the human body can cause long-term health concerns and environmental challenges. Many of these plasticisers are esters of polyvalent acids and phthalic acid has previously been predominant but various alternatives are now being more widely explored. The eventual distribution of these compounds depends not just on solubility in aqueous media and on vapour pressure but also on their interaction with other materials, particularly lipids and amphiphiles. This review provides an overview of both the basic physical data (solubility, partition coefficients, surface tension, vapour pressure) that is available in the literature and summarises what has been learnt about the molecular interactions of various plasticisers with surfactants and lipids.
\end{abstract}

(C) 2020 The Authors. Published by Elsevier B.V. This is an open access article under the CC BY-NC-ND license (http:// creativecommons.org/licenses/by-nc-nd/4.0/).

\section{Contents}

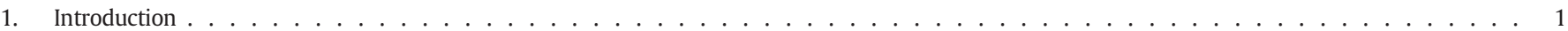

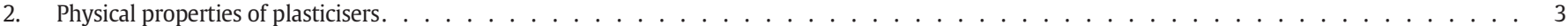

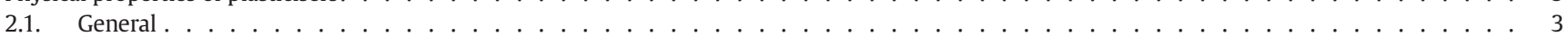

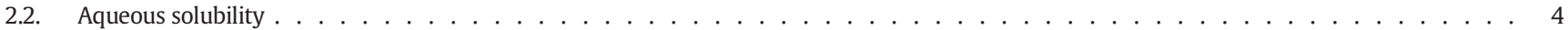

2.3. Oil-water partition coefficients $\ldots \ldots \ldots \ldots \ldots$

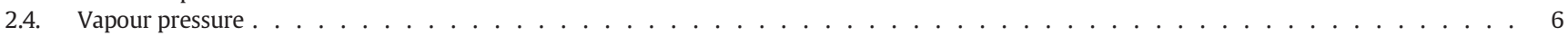

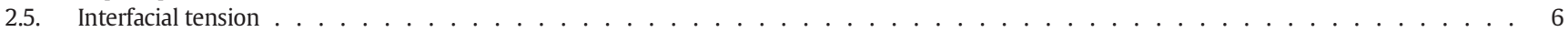

2.6. Plasticiser interaction with amphiphiles . . . . . . . . . . . . . . . . . . . . . . . . . . . . 7

3. Some consequences of the physical properties of plasticisers interactions with amphiphiles . . . . . . . . . . . . . . . . . . . . . . . 8

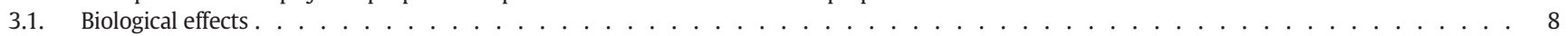

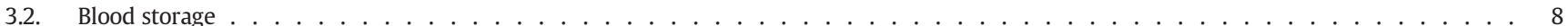

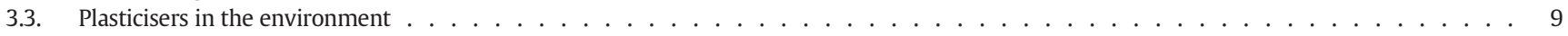

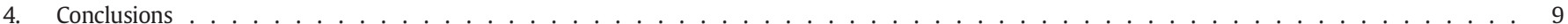

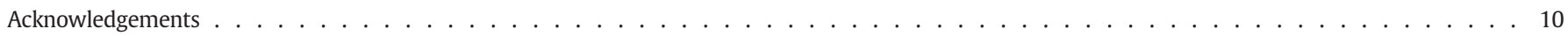

Appendix A. Supplementary data . . . . . . . . . . . . . . . . . . . . . . . . . . . . 10

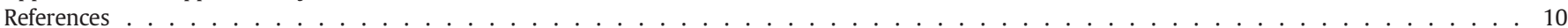

it This review is contributed to the special issue of Advances in Colloid and Interface Science that honours the work of Dotchi Exerowa and Dimo Platikanov in the hope that it will help others with continuing studies of interfaces and mixtures.

* Corresponding author

E-mail address: Adrian.Rennie@physics.uu.se (A.R. Rennie).

\section{Introduction}

There is increasing concern about possible hazards to health and the environment from a number of plastic products. Although the use of non-biodegradable polymeric materials is a well understood environmental concern, other issues arise that might also cause significant 
effects when small molecule additives leach into the environment and they are now recognised as a health concern [1]. These molecules can be unpolymerized monomers, plasticisers and other additives such as pigments, antioxidants and processing aids. This review concerns the physical properties of plasticisers and how such properties relate to environmental and biological impact by interaction with amphiphiles. This review will not discuss specifically the interactions between plasticisers and polymers and their role in the intended products.

There is a considerable amount of scientific work that reports analytical studies of concentrations of various pollutants [2] and some biological consequences of exposure [3]. In some cases human exposure is a direct consequence of the use of plastic devices in medical procedures $[4,5]$. Although the plasticisers in most of these devices are considered to be harmful, or at best undesirable, there have been unexpected advantages in a few cases. Most prominently, the viability of blood stored in polyvinyl chloride (PVC) bags that are plasticised with di-2ethylhexylphthalate (DEHP) has been found to be better, can be stored for longer, than that of various alternatives [6-11]. DEHP, because of its adverse effects on human health, has been banned from use in many applications but because of this particular advantage is still accepted for use in production of blood storage bags [12]. For reasons such as this, it is necessary to find a basic understanding of how both materials already in use as well as possible alternatives interact with blood cells and more generally with amphiphiles, molecules that have both hydrophobic and hydrophilic properties (e.g. lipids and surfactants), and biological macromolecules.

Although the consequences of pollution have been documented, it has been difficult to achieve an understanding at a molecular level as to how materials like plasticisers interact with cells, plants and organisms. There have been a few specific reports of investigations of plasticisers with lipids but even the necessary accurate background information about solubility, partition coefficients and interfacial tension has been difficult to find.

The most widely used plasticisers have been esters of phthalic acid. A wide range of different alcohols are used to form these materials with hydrocarbon chain lengths of up to 12 carbon atoms. Diethylhexyl phthalate has been particularly common, known as DEHP, and wellsuited for PVC. As practical use of PVC will often involve up to $30 \%$ weight or more of plasticiser and global consumption of PVC is of the order of 40 million tonnes per year [13], one third of which is plasticised, this represents a large amount of plasticiser that can be dispersed to the environment. Sometimes DEHP is known less precisely as dioctylphthalate and this can cause confusion if a distinction with the specific isomer di-noctylphthalate is not made clearly. Some commonly used plasticisers with their basic physical properties are listed in Table 1. Even such simple data as that shown in this table is prone to discrepancies. As many of the materials form glasses rather than crystals, the melting temperature is sometimes simply either a 'pour point' or a glass transition temperature. The determinations of boiling points are liable to problems with degradation and in practice, most of these materials could only be distilled at reduced pressure.

At first one might think that compatibility of plasticisers with the polymer and the transport through a solid might limit the leaching of material. Perhaps a key realisation is that very large amounts of plasticisers are used, particularly for PVC, and that the very high source concentration is an important factor in determining the overall amount that will leach from a product and can be transported into human tissue and the environment. Harmful effects from plasticisers arise from long term exposure, and due to the hydrophobic nature of plasticisers bioaccumulation is a concern. This review discusses primarily the properties of materials that have been commonly used as plasticisers, which are phthalate esters These materials have been much more widely investigated than other recently introduced alternatives. There is more available data in the literature for phthalates with varying chain length and these results can provide important physical ideas and guidance as to the validity of predictive tools that may be relevant to a broader range of materials. The properties of the potential replacements for phthalate esters are also discussed when data are available. A list of commonly used plasticisers with their basic physical properties is provided as Table 1, and their corresponding molecular structures are shown in Fig. 1.

Older data on toxicity of phthalate esters has been reviewed by Peakall [14] and $\mathrm{LD}_{50}$ for various mammals presented that are typically a few per cent or less of body mass. Significant health effects, e.g. developmental toxicity, carcinogenicity, may be expected at much lower amounts. More recently hazards that arise from alternative plasticisers that are usually esters of other polyvalent acids have been reviewed by Bui et al. [15] who have identified that some necessary data are not available. The purpose of this review is not to describe again the literature on toxicity or specific environmental behaviour but rather to provide access to physical properties that can be key to understanding the distribution and interactions of these materials generally and consequently influence human health and the environment. Certain physical properties such as water solubility, are strongly related to bioavailability, which in turn affects toxicity. Oil-water partitioning coefficients relate to distribution of the substances, and thus to bioaccumulation. The spreading on water surfaces and subsequent effects on surface tension has large environmental impact, for example in changing stability of aerosols. Thus understanding the physical properties of these substances also allows us to better predict the consequences of their distribution.

This short review provides a guide to the literature, identifying previous work that has specifically described plasticiser interactions but also the provision of more general background data that is needed to plan further investigations. The structure of the article is that first physical properties that relate to solubility, transport and vapour pressure

Table 1

Identification and some physical properties of common plasticisers.

\begin{tabular}{|c|c|c|c|c|c|c|c|}
\hline \multirow[t]{2}{*}{ Number } & \multirow[t]{2}{*}{ Name } & \multirow[t]{2}{*}{ Abbreviation/Acronym } & \multirow[t]{2}{*}{ CAS No. } & \multirow{2}{*}{$\frac{\text { Molecular Mass }}{\mathrm{g} \mathrm{mol}^{-1}}$} & \multirow{2}{*}{$\frac{\text { Melting Point }}{{ }^{\circ} \mathrm{C}}$} & \multirow{2}{*}{$\frac{\text { Boiling Point }}{{ }^{\circ} \mathrm{C}}$} & \multirow{2}{*}{$\frac{\text { Density }}{\mathrm{g} \mathrm{cm}^{-3}}$} \\
\hline & & & & & & & \\
\hline 1 & Diethyl phthalate & DEP & $84-66-2$ & 222.24 & -4 & 295 & 1.12 \\
\hline 2 & Di-n-butyl phthalate & DnBP & $84-74-2$ & 278.35 & -35 & 340 & 1.05 \\
\hline 3 & Diisobutyl phthalate & DIBP & $84-69-5$ & 278.35 & -37 & 320 & 1.04 \\
\hline 4 & Di 2-ethylhexyl phthalate & DEHP & $117-81-7$ & 390.56 & -50 & 385 & 0.99 \\
\hline 5 & Di-n-octyl phthalate & $\mathrm{DnOP}$ & $117-84-0$ & 390.56 & -25 & 386 & 0.98 \\
\hline 6 & Diisononyl-cyclohexane 1,2-dicarboxylate & DINCH & $474,919-59-0$ or $166,412-78-8$ & 424.67 & -54 & 394 & 0.95 \\
\hline 7 & Trioctyl trimellitate & TOTM & $3319-31-1$ & 546.79 & -7 & $355^{\mathrm{a}}$ & 0.99 \\
\hline 8 & Acetyl tributyl citrate & АТВC & $77-90-7$ & 402.48 & -80 & 172 to 174 & 1.05 \\
\hline 9 & Butyryl trihexyl citrate & BTHC & $82,469-79-2$ & 514.35 & -55 & 247 & 1.00 \\
\hline 10 & Diethylhexyl adipate & DEHA & $103-23-1$ & 370.57 & -68 & 417 & 0.93 \\
\hline
\end{tabular}

a A wide range of values are reported by manufacturers (258 to $414^{\circ} \mathrm{C}$ ) possibly due to degradation. The value quoted is from reference [16]. 
Diethyl phthalate (DEP)

1<smiles>CCOC(=O)c1ccccc1C(=O)OCC</smiles>

Diisobutyl phthalate (DIBP)

3<smiles>CC(C)COC(=O)c1ccccc1C(=O)OCC(C)C</smiles>

Trioctyl trimellitate (TOTM)<smiles>CCCCCCCCOC(=O)c1ccc(C(=O)OCCCCCCC)cc1C(=O)OCCCCCCC</smiles>

Diisononylcyclohexane dicarboxylate<smiles>CCCCCCCCOC(=O)C1CCCCC1C(=O)OCCCCCCCC(C)C</smiles>

2<smiles>CCCCCOC(=O)c1ccccc1C(=O)OCCCC</smiles>

Diethylhexyl phthalate (DEHP)

4<smiles>CCCCCC(CC)(CCC)CCCCC</smiles>

Di-n-octyl phthalate (DnOP)

6<smiles>CCCCCCCCCCCOC(=O)c1ccccc1C(=O)OCCCCCCC</smiles>

8<smiles>CCCCOC(=O)CC(CC(=O)OCCCC)(OC(C)=O)C(=O)OCCCC</smiles>

Butyryl trihexyl citrate (BTHC)

9<smiles>CCCCCCOC(=O)CC(CC(=O)OCCCCCC)(OC(=O)CCC)C(=O)OCCCCC</smiles>

Diethylhexyl adipate (DEHA)

10<smiles>CCCCC(CC)COC(=O)CCCCC(=O)OCC(CC)CCCC</smiles>

Fig. 1. Molecular structures for the commonly used plasticisers listed in Table 1.

are described and available data are presented. Information about the properties of these materials at interfaces such as adsorption and interfacial tension are then described. There is subsequently an account of the specific studies that have been made of interactions of plasticisers with amphiphiles such as surfactants and lipids. These results are then placed briefly in the context of challenges posed to health and to the environment.

In only a few cases are uncertainties reported for experimentally measured data. This does lead to some difficulties and 'error bars' can only be shown when these are provided. However, some idea of uncertainty can be derived from the independent measurements reported by different authors and so these are shown in several Figures when possible. When very large deviations with many orders of magnitude differences have been reported, only the results most likely to be reliable are shown in the figures in this paper but a full record of data is provided in the Supporting Information.

\section{Physical properties of plasticisers}

\subsection{General}

In this section we will describe the data available in the literature for plasticisers that is particularly relevant to the understanding of interactions at interfaces and with other amphiphiles. In this regard, it is expected that solubility and oil/water partition coefficients are likely to be important as they will determine the overall distribution of material in bulk phases at equilibrium. The particular properties of interfaces and membranes are often governed by other contributions to free energy that are usually described by interfacial or surface tensions. These data are valuable to understand spreading of plasticisers at interfaces. Available data and some correlations based on simple models that are observed will be presented. 
Biological and environmental impact is very often determined by their physical properties. Aqueous solubility determines bioavailability, partitioning coefficients affects accumulation in cell membranes and surface tension and film formation can affect aerosol formation and stability. Thus, knowledge of physical properties is an important step towards being able to predict quantitatively and to understand what happens when molecules are released into the environment. Comparison of models with experimental data is important as this allows the likely validity of predictions for new materials to be assessed. Extending the range of comparison for homologous series, sometimes even beyond the materials that are widely used as plasticisers is helpful to make this assessment of the prediction tools.

\subsection{Aqueous solubility}

The properties of many common phthalate esters are well studied due to their potential environmental impact. However, many plasticisers that have been introduced more recently as alternatives with lower toxicity lack detailed physiochemical data, and for these materials predictive tools and models are useful to get an idea of their properties. One of the most important properties in determining the transport of organic materials through media, and the amount of material that is leached from polymers, is their aqueous solubility. There is a substantial recent review of experimental data about aqueous solubility of esters by Góral et al. [17] but this has not yet attracted much attention from the interface science and environmental science communities. The possibility to predict physical properties of new potential plasticisers would help to establish what molecules are suitable in this regard. There are readily available software packages that can be used to this effect, one such tool is the EPIsuite, that has an array of programs for predicting properties of input chemical structures [18].

EPIsuite is made up of several different programs that can estimate different physical properties, for example oil-water partitioning coefficients or melting points. The estimation method used for different programs vary but is always based on creating an empirical model based on a library of compounds with known parameters. In this review, we are primarily using two programs, KOWWIN that estimates oil-water partition coefficients and WSKOW that estimates water solubility. A brief explanation of how these programs work can be found here. Other options for predictions of physical properties also exist, such as the SPARC program by Karickhoff et al. [19] SPARC operates on a similar basis to WSKOW from EPIsuite by using molecular properties associated with structural elements. Letinski et al. compare SPARC and WSKOW with their experimental data, and although they conclude that SPARC fits the data better, the difference is not significant compared to the variance in experimental data found in the literature [20]. Another possible approach would be using molecular dynamics simulations to obtain physical properties. A major drawback of this method is the computational power needed to obtain useful data. To allow for low solubility, the box size used in the simulation will have to be large which also makes the simulation more resource intense. The feasibility of predicting physical properties of low solubility esters by molecular dynamics is therefore quite low. Our review primarily focuses, in this respect, on comparisons of literature data to results from EPIsuite due to the ease of use and its free availability.

The program KOWWIN uses a 'fragment constant'method that is also known as an atom/fragment contribution (AFC) method. It divides a molecular structure into fragments that are assigned a value that has been empirically determined. The core of a fragment is made up of non-hydrogen atoms that could be either functional groups (e.g. isothiocyanate, $-\mathrm{N}=\mathrm{C}=\mathrm{S}$ ) or part of the carbon backbone (e.g. a $-\mathrm{CH}_{2}$ group). For example, isopropanol would be divided into two $-\mathrm{CH}_{3}$ groups, one $\mathrm{CH}$ group and one $-\mathrm{OH}$ group. In addition to fragments, correction factors are used for more complicated structures that cannot easily be divided into just fragments, such as the position of polar groups on an aromatic ring.
WSKOW uses one of two different equations to estimate the solubility, depending on the available information about the compound. If a melting point is not provided, the following equation is used:

$$
\begin{aligned}
\log \left(\mathrm{S} / \mathrm{mol} \mathrm{L}^{-1}\right)= & 0.796-0.854 \log \mathrm{K}_{\mathrm{ow}}-0.00728 \mathrm{M}_{\mathrm{W}} \\
& +\Sigma \text { Corrections }
\end{aligned}
$$

where $\mathrm{S}$ is the solubility, $\mathrm{K}_{\mathrm{ow}}$ is the oil-water partition coefficient and $\mathrm{M}_{\mathrm{W}}$ is the molecular weight. If a melting point, $\mathrm{T}_{\mathrm{m}}$, is known, the program will instead use the following equation $\left(\mathrm{T}\right.$ in $\left.{ }^{\circ} \mathrm{C}\right)$ :

$$
\begin{aligned}
& \log \left(\mathrm{S} / \mathrm{mol} \mathrm{L}^{-1}\right) \\
&= 0.693-0.96 \log \mathrm{K}_{\mathrm{ow}}-0.0092\left(\mathrm{~T}_{\mathrm{m}}-25\right)-0.00314 \mathrm{M}_{\mathrm{W}} \\
&+\Sigma \text { Corrections }
\end{aligned}
$$

Any value for $\mathrm{T}_{\mathrm{m}}$ used that is $<25{ }^{\circ} \mathrm{C}$, i.e. a liquid at room temperature, will result in the same estimation by the software. For the purpose of this calculation it does not matter if the melting point is -20 or $20^{\circ} \mathrm{C}$. Thus, knowing the actual melting point is only important for substances with a melting point above $25^{\circ} \mathrm{C}$. For liquids at room temperature the outcome is then independent of the temperature. If a $\mathrm{K}_{\mathrm{Ow}}$ value is known for the compound it can be entered into the program and the program will then use this value. If no value is provided, the program will use the value found in its data base. If there is no value in the data base, the software will estimate an octanol-water partition coefficient by using the KOWWIN methodology described above. The corrections are applied based on functional groups present in the molecular structure, corrected once for each functional group. In this review, we are looking at plasticisers, which are liquid at room temperature and all estimates presented are obtained with the second equation.

There have been previous efforts to collect the available literature data on phthalate solubility by Staples et al. [2]. Data from several sources have been collated in a previous study [21]. Staples et al. explain some of the difficulties in determining the solubility of hydrophobic and high molecular weight compounds, like DEHP, DnOP. The shorter chain phthalate esters that are reasonably soluble in water, have well determined solubilities that are corroborated by several sources, but the higher molecular weight phthalate esters have reported solubilities that differ by several orders of magnitude $[2,22,23]$. This discrepancy is expected to have multiple origins, one is the difficulty in separating observation of emulsions or microemulsions from true solubilization. The detection limit for different experimental methods will also impact data for some of the molecules with very low solubility, making it difficult to establish. Following the review of Staples et al., Ellington [22] presented data on the high molecular weight phthalate esters, which had been identified as a problem and that data matches well with the expectations for water solubility for such compounds. Letinski et al. describe a slow-stirring method for measuring the solubility of high molecular weight esters that is more reliable than techniques employed previously [20]. Data from the review by Staples et al. as well as from Ellington, were used by Cousins and Mackay [23] to establish a relation between physical properties and chemical structure. The data compiled by Cousins and Mackay, with relevant additions, is used for comparisons in the present review. Some of the data points have been excluded in the figures presented here as the deviation from expected trends are very large and we have chosen to indicate only the likely values. The full data are shown in the figures in the supporting information. The literature values for water solubility, the calculations by Cousins and Mackay as well as estimates made using the EPIsuite program WSKOW are shown in Fig. 2. Data from short chain phthalate esters, that are not normally used as plasticisers, are also included in the presented data sets. This comparison with more complete data results in greater confidence in the predictive power and makes it easier to evaluate the models. There is a clear relationship between the number of carbons and the solubility. The disparity between different 


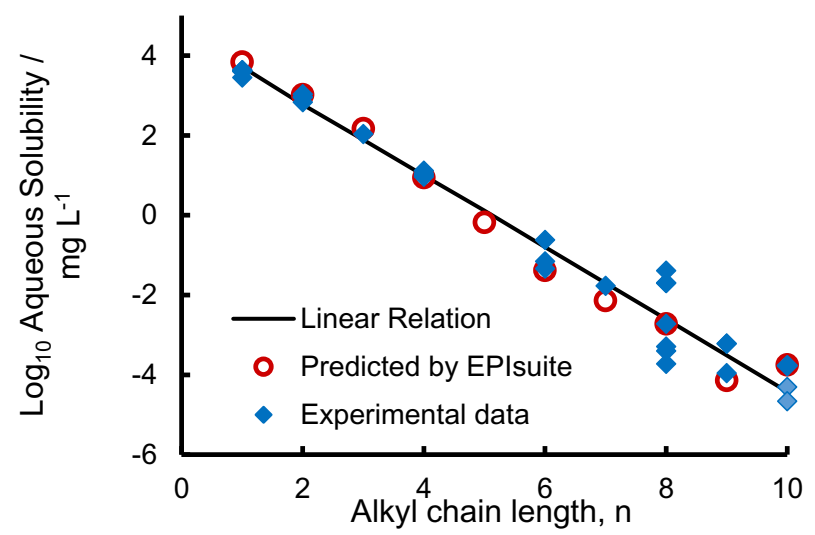

Fig. 2. Aqueous solubility for phthalate esters as a function of alkyl chain length. Experimental data compiled by Cousins and Mackay with additions from Letinski et al. [20]. Experimental data measured at $25{ }^{\circ} \mathrm{C}$. The linear relationship of the logarithm of solubility with molecular size proposed by Cousins and Mackay and calculations by the EPIsuite program, WSKOW. The data that are omitted for reasons of large deviations are shown, for information, in Fig. S1 and all numerical values and their source are listed in Table S1.

measurements becomes apparent when there are eight carbons or more in the side chain. The difference between the highest and the lowest measured solubility in the case of eight carbon chains is four orders of magnitude. Both the model used by Cousins and Mackay, and the EPIsuite software predict that the solubility follows a logarithmic dependence on the number of carbons.

More recently, Ishak et al. investigated the temperature dependence of dibutyl phthalate (DBP) and its isomer diisobutyl phthalate (DIBP) [24]. They show that DBP is more hydrophobic than its counterpart through a combination of measurements of relative water solubility and determination of octanol-water partition coefficients. The temperature dependent solubility for both isomers is shown in Fig. 3.

There is a noticeable difference between the behaviour of the two isomers, a solubility difference can be observed even at low temperatures such as $25^{\circ} \mathrm{C}$ with the branched diester being more water soluble and there is a stronger temperature dependence. This data highlights the difference between isomers, that are in some models assumed to be identical. Similar results are also seen for dinonyl phthalate where the solubility of diesters with branched chains are higher than linear chains as reported by Letinski et al. [20] In the same paper it was noted that DEHP also has a higher solubility than DnOP, however in both cases data is only available at $22{ }^{\circ} \mathrm{C}$. Aqueous solubility for DBP and DIBP obtained by Ishak et al. [24] and calculations are compared in Table 2. The calculation of the solubility by Cousins and Mackay is simply a linear relation with the molecular volume and so does not

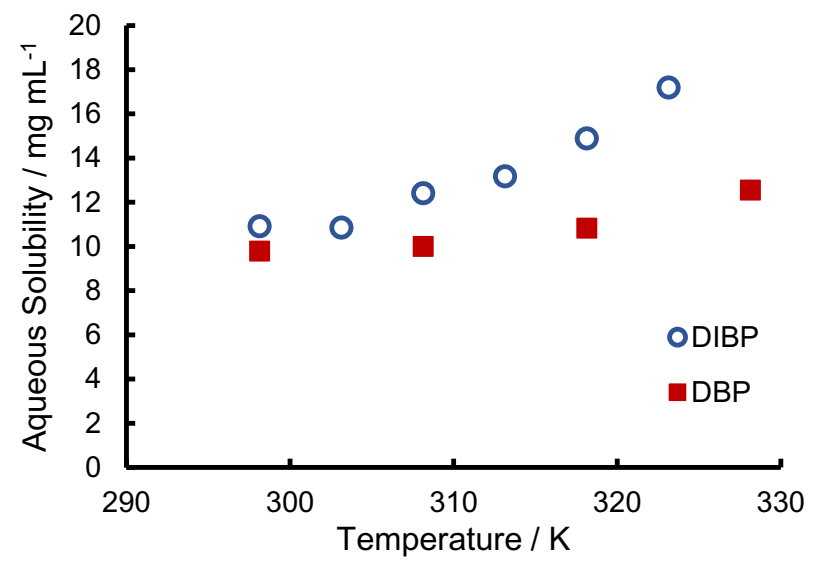

Fig. 3. Aqueous solubility of dibutyl phthalate (DBP) and diisobutyl phthalate (DIBP) as a function of temperature in Kelvin. Data from Ishak et al. [24].
Table 2

Measured solubility by Ishak et al. compared to calculated solubility. Data corresponds to a temperature of $25^{\circ} \mathrm{C}$

\begin{tabular}{lll}
\hline Source & $\begin{array}{l}\text { Solubility } \\
\mathrm{DBP} / \mathrm{mg} \mathrm{L}^{-1}\end{array}$ & $\begin{array}{l}\text { Solubility } \\
\text { DIBP } / \mathrm{mg} \mathrm{L}^{-1}\end{array}$ \\
\hline Ishak et al. (experiment) & 9.79 & 10.92 \\
Cousins and Mackay (calculation) & 9.9 & 9.9 \\
EPIsuite, WSKOW (model) & 6.89 & 9.59 \\
\hline
\end{tabular}

differ significantly between isomers but is otherwise a close approximation. In contrast, EPIsuite correctly predicts the solubility to be higher for DIBP than DBP but also deviates more from the measured values.

It is valuable to note that although data for solubility in pure water is important, there can be quite different amounts of dissolved organic material when there are other components present, particularly lipids and proteins. For example, as will be discussed later biological fluids such as blood can contain much more DEHP than pure water [25].

\subsection{Oil-water partition coefficients}

Oil-water partition coefficients are commonly reported in conjunction with water solubility and as a measure of a molecule's hydrophobicity, it can also be used to estimate solubility and because of this connection they are often reported together. However, one should be aware that simple determination of separation into octanol and water as is commonly reported may not give a complete general picture of behaviour, particularly when one component has a tendency to associate [26]. Octanol-water coefficients from Staples et al. are compared to EPIsuite [18] estimates and calculations by Cousins and Mackay in Fig. 4. As for the data on solubility, there is greater discrepancy between measurements for higher molecular weight phthalates. There is a general lack of data for longer chain lengths, with the exception of the octyl phthalates. This makes it more difficult to evaluate theoretical calculations and estimates.

Comparisons between octanol-water partition coefficients of DBP and DIBP are in Table 3. Data from Tables 2 and 3 show the differences between two isomers. Experimentally they have different octanolwater partition coefficients and water solubility, this is also predicted by EPIsuite, while the relation from Cousins and Mackay does not differentiate between the properties of these isomers.

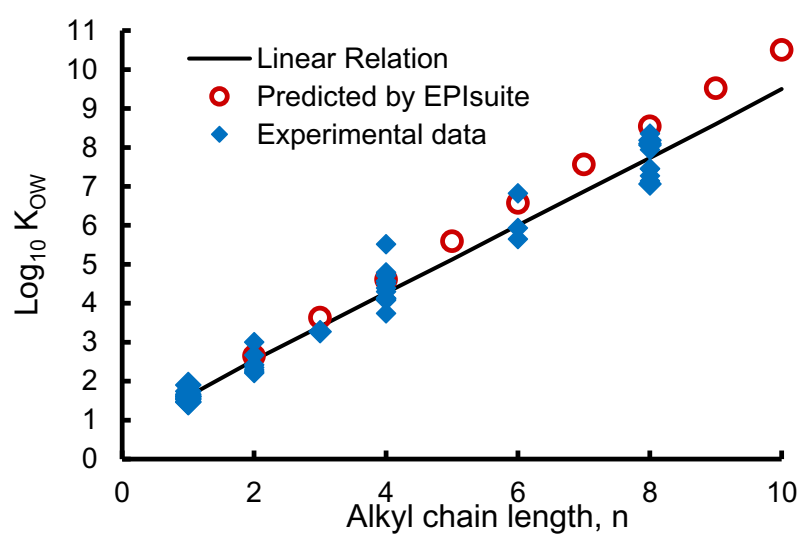

Fig. 4. The $\log _{10}$ of octanol-water partition coefficients for phthalate esters as a function of alkyl chain length. Data compiled by Cousins and Mackay and were collected at $25^{\circ} \mathrm{C}$. The linear model of Cousins and Mackay as well as calculations from the EPIsuite program [18], KOWWIN, are shown. Numerical values for the data are provided in Table S2 in the Supplementary Supporting Information. 
Table 3

Measured oil-water partition coefficients by Ishak et al. compared to calculated $\mathrm{K}_{\mathrm{OW}}$ from Cousins and Mackay as well as estimates using EPIsuite. Data corresponds to a temperature of $25^{\circ} \mathrm{C}$.

\begin{tabular}{llll}
\hline Method & Source & Log $\mathrm{K}_{\mathrm{OW}}$ DBP & Log $\mathrm{K}_{\mathrm{OW}}$ DIBP \\
\hline Ishak et al. (experiment) & Reference 24 & 4.53 & 4.34 \\
Cousins and Mackay (calculation) & Reference 23 & 4.27 & 4.27 \\
EPIsuite. KOWWIN (model) & Reference 18 & 4.61 & 4.46 \\
\hline
\end{tabular}

\subsection{Vapour pressure}

In some systems, loss of material as vapour may be a dominant process, in part because of the large volumes of air that are available and that can be readily exchanged. The Clausius-Clapeyron relation suggests that for most materials there would be a linear relationship between the logarithm of vapour pressure and the reciprocal of the absolute temperature with the gradient of such plots determined by the enthalpy of vaporisation. This transition enthalpy, in turn, is strongly correlated with molecular mass or molecular size in homologous series of compounds with similar chemistry. Acree and Chickos have provided extensive recent reviews of enthalpies of phase change that include data for a number of materials that are used as plasticisers [27,28]. A substantial but older list of vapour pressures and their correlation with $\Delta \mathrm{H}_{\mathrm{vap}}$ was provided by Thomsen and Carlsen [29]. For some materials there is more precise new data such as that of Ishak et al.[24] and by Gobble and Chickos [30]. As seen by the data plotted in Figs. 5 and 6, the agreement with the expected models is good and there is little apparent advantage in using more complicated calculations.

\subsection{Interfacial tension}

There are several reports of measurements of the air liquid interfacial tension for various phthalate esters. Aveyard et al. [31] measured a homologous series of esters from diethyl phthalate to didecylphthalate using a du Nouy ring at $25^{\circ} \mathrm{C}$. For two phthalate materials there are data measured by other authors over a range of temperatures: Ricci et al. [32] measured dioctylphthalate, although the isomer is not specified, and Caetano et al. [33] studied di-isodecylphthalate. It is interesting to note that there have been various diverse motivations for these studies that ranged from the design of microemulsions, use of mixtures of oils in microgravity, to development of reference fluids for viscosity measurements. There are a few other measurements of individual materials [34-36] that have been plotted together with these data in Fig. 7. The overall agreement between data measured on different samples and by different methods is reasonable and there is marked trend for the surface tension to decrease as the overall molecular size increases, with the number of carbon atoms in the alkyl chains. There is also a clear trend for the surface tension to decrease with increasing temperature. Ricci et al. [32] described a linear relationship with a temperature coefficient of $-0.0815 \mathrm{mN} \mathrm{m}^{-1} \mathrm{~K}^{-1}$ for the dioctylphthalate. The di-isodecylphthalate can be analysed in a similar way and although the temperature range is more limited, the data reported by Caetano et al. [33] gives $-0.072 \mathrm{mN} \mathrm{m}^{-1} \mathrm{~K}^{-1}$.

There are apparently fewer investigations of plasticisers that are not based on phthalic acids but there is a detailed report [37] including temperature dependence for the surface tension of tris(2-ethylhexyl) trimellitate (TOTM) as a pure liquid. The surface tension at $25^{\circ} \mathrm{C}$ corresponds to $30.3 \mathrm{mN} \mathrm{m}^{-1}$. The temperature coefficient of the surface tension for this material is $-0.077 \mathrm{mN} \mathrm{m}^{-1} \mathrm{~K}^{-1}$. A single value for the surface tension of 1,2-cyclohexane-dicarboxylic acid diisononyl ester, DINCH [38], of $30.7 \mathrm{mN} \mathrm{m}^{-1}$ has been reported.

Another interesting study of interfaces was made by Thomsen et al. [39] where measurements of the surface tension of solutions of various phthalate esters in water were made. Solutions were made by first

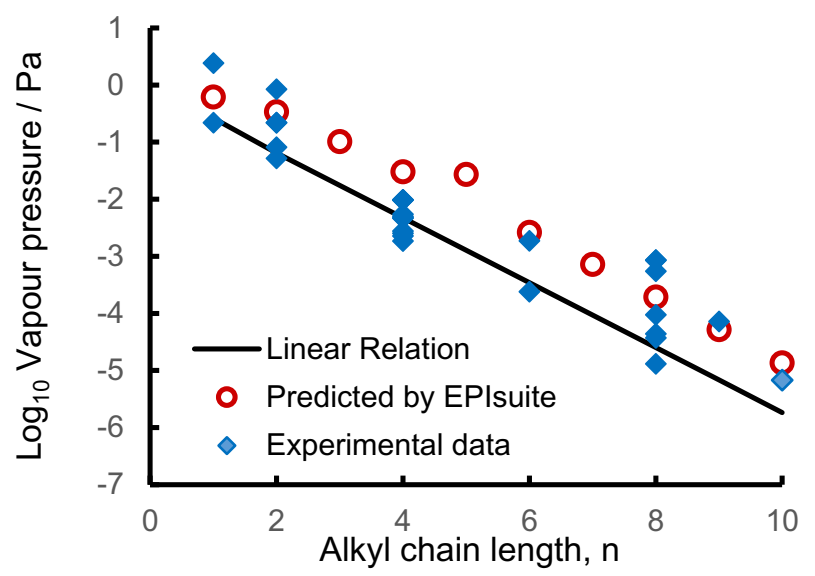

Fig. 5. Vapour pressure of phthalate esters as a function of alkyl chain length. Data compiled by Cousins and Mackay with extra data from Thomsen and Carlsen, and Ishak et al. Data collected at $25^{\circ} \mathrm{C}$. The linear relation of Cousins and Mackay [23] as well as calculations from the EPIsuite program [18], MPBPVP, are also shown. The numerical values and the sources for individual data points are shown in Table S3 (Supplementary Supporting Information).

dispersing the organic material in methanol and the resulting low concentration of the alcohol was judged not to cause significant changes in the reported results. There are clear reductions in the surface tension with increasing concentration and, for all the materials investigated there are sharp breaks in the curves at specific concentrations that are described as critical aggregation concentrations in analogy with critical

(a)

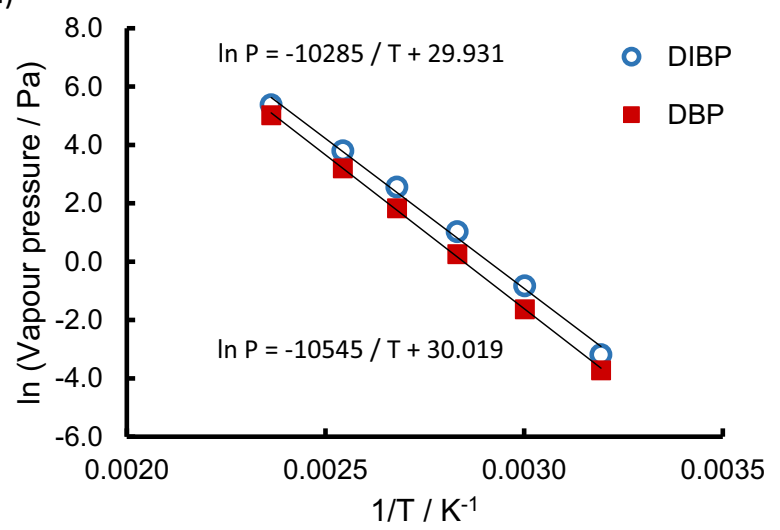

(b)

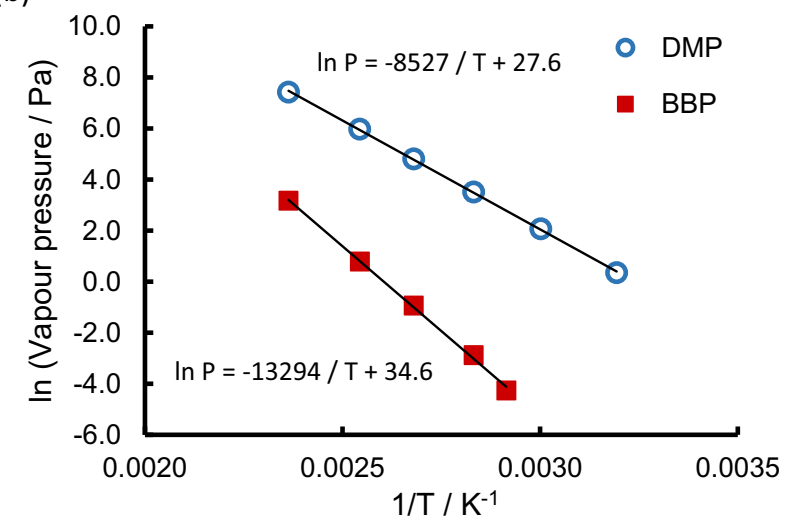

Fig. 6. Vapour pressure as a function of temperature for (a) dibutyl phthalate (DBP) and diisobutyl phthalate (DIBP) and (b) benzyl butyl phthalate and dimethylphthalate. Data from Ishak et al. [24]. 
micellization concentrations that are observed for surfactants. The data were analysed, as for soluble surfactants, using the Gibbs equation relating the gradient of plots of surface tension with the logarithm of the concentration to the surface excess. The surface tension of the aqueous solutions only reached about $52 \mathrm{mN} \mathrm{m}^{-1}$ for the highest concentration of diethylphthalate, DEP, and the reduction in surface tension was much less for larger alkyl chains reaching only about $67 \mathrm{mN} \mathrm{m}^{-1}$ for DEHP. As for the pure liquids, the surface tension decreases with increasing temperature. The significant change in gradient of the plots of the surface tension with $\log$ (concentration), of the order of a factor of five or ten, would be indicative of a significant change in activity or state of aggregation above the identified concentrations. The amount that is calculated as the surface excess and the known approximate density suggests that for dihexylphthalate, a thick layer of more than one molecule would be formed.

A further type of investigation of plasticisers at interfaces has involved spread films that are investigated on a Langmuir trough. In the presence of other amphiphiles such as the lipid 1,2-dimyristoyl-snglycero-3-phosphorylcholine (DMPC), DEHP and DINCH can be spread from chloroform solutions on to water surfaces [40]. Measurement of compression isotherms have indicated that there are limits of about $20 \%$ to $40 \%$ of the ester that can be retained in the surface layer when compressed. A recent study [41] has suggested that layers can be formed also with hexadecanoic and octadecanoic acids. These authors also indicated in various plots of data that films were present that could be compressed even without the fatty acids. Such results could not be reproduced on pure water by the present authors. Li et al. [41] also state that DEHP does not spread on artificial seawater.

\subsection{Plasticiser interaction with amphiphiles}

Bonora et al. [42,43] investigated the interaction between both phthalate and sebacate (1,10 n-decandioate, see Fig. S5 in the supplementary information) plasticisers and multi-lamellar 1,2dipalmitoylphosphatidylcholine (DPPC) liposomes by differential scanning calorimetry (DSC). Phthalate esters (DEP, DBP, DEHP and DnOP) were found to reduce the temperature of the main transition already at low plasticiser content $(<1 \%)$. The largest effect was seen for the ethyl and n-butyl esters, and the effect becomes smaller with longer chains. Branching also affected the melting, or 'gel', transition temperature, with DEHP having a larger effect than DnOP but smaller than DEP and DBP. Data from Bonora et al. [42] are shown in Fig. 8a. The observed difference between phthalate esters was explained as arising from van der Waals interactions between the ester chains and the lipids. DnOP can better fill the space between lipid molecules, thus increasing the interactions between it and the lipid, which offsets the increase in free volume that results in the decrease of the transition temperature. A branched chain fits poorly between the lipids, which in turn means that the transition temperature decreases relative to that for an unbranched chain.

When phthalate esters are compared to sebacate esters, Bonora et al. [43] found that the short chain sebacate esters do not affect the transition temperature as much as short-chain phthalates. These data are shown in Fig. 8b. The difference in flexibility between phthalates and sebacates are described as the source of this difference. Due to their aromatic moiety, phthalates are more rigid than sebacates which instead have a more flexible aliphatic structure. On account of their rigidity, the phthalates do not have strong interactions between the carbonyl groups and the polar head group of DPPC, and thus even short phthalates are dominated by hydrophobic interactions. In contrast, sebacates have significant dipole interactions and provided that the chains are short enough, the polar interactions dominate. For this reason, the sebacates do not penetrate deep into the lamellar structure.

Several groups have also reported increased leaching of DEHP in the presence of lipids, either as as emulsions in the tube $[4,44]$ or as a lipidcoating on the inside of the PVC tube [45]. Münch et al. reported that (a)

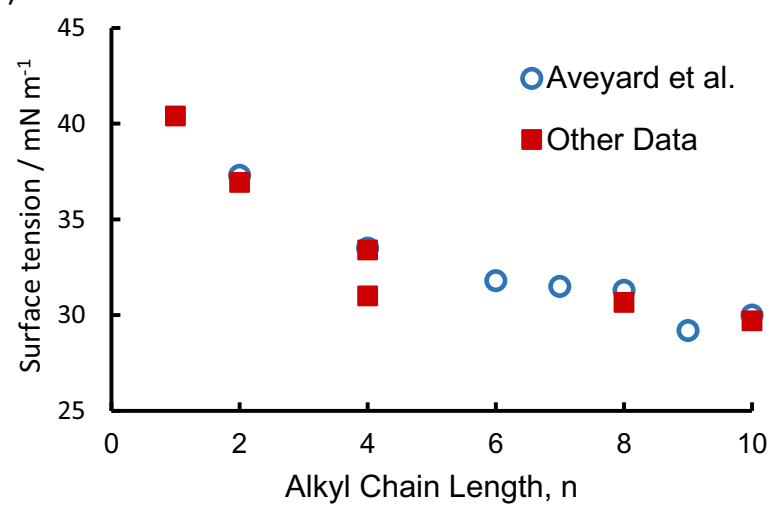

(b)

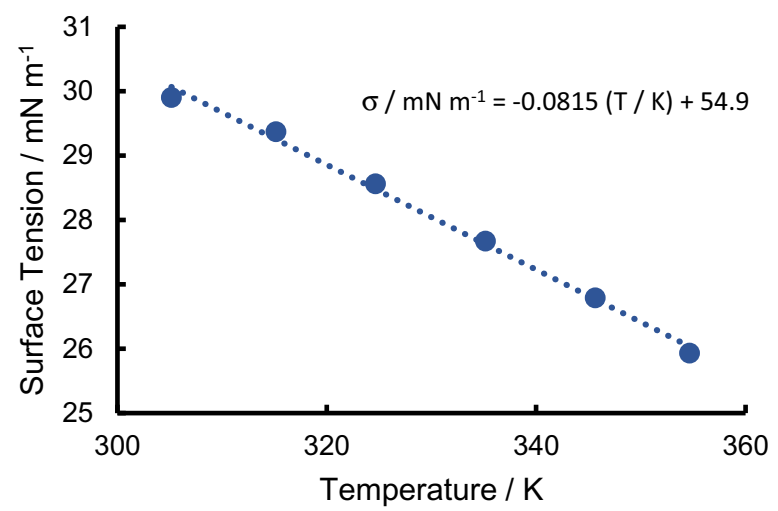

Fig. 7. (a) Surface tension, $\sigma$, at $298 \mathrm{~K}\left(25^{\circ} \mathrm{C}\right)$ for various phthalate esters against length of the alkyl chains. The value of $n$ is the number of carbon atoms in each alkyl chain. The data demonstrate generally good agreement between measurements made by different groups. The source of the individual experimental data points and the sources for the data are shown in Table S4 (Supplementary Supporting Information) (b) The temperature dependence of surface tension is illustrated by the data for dioctyl phthalate of Ricci et al. [32].

this effect was larger for tri-2-ethylhexyl trimellitate (TOTM), however the rate of leaching is still several hundred times slower than for DEHP [45]. Faessler et al. reported that in the presence of a lipid emulsion, DEHP leached 10-100 times faster than other investigated plasticisers (DEHT and DINCH). Leaching of plasticisers from the polymer matrix depends on the size and shape of the plasticiser [46] and Marcilla et al. reported that phthalates have a smaller tendency for migration than citrate and adipate based plasticisers [47]. This apparently indicates that the fast leaching of DEHP from PVC is not related to its diffusion in PVC, but rather its properties at the interface or in the adjacent bulk phase.

Waters et al. [48] determined the partition coefficient of three phthalate esters (DMP, DEP, DPP) in sodium dodecyl sulfate (SDS) micelles by using micellar liquid chromatography. As with oil-water partition coefficients for the same phthalates, the partitioning into SDS micelles increase with longer alkyl chains. The change in Gibbs free energy associated with the partitioning, as well as its entropic and enthalpic contributions were also determined and the authors conclude that the partitioning is an enthalpically driven process. Another study investigated the partitioning of DMP in two different micellar systems, SDS and dodecyl trimethylammonium bromide (DTAB) by using isothermal titration calorimetry (ITC) [49]. They found that SDS micelles contained twice as many DMP molecules as DTAB micelles and furthermore that while partitioning of DMP into SDS was an exothermic process, partitioning into DTAB was an endothermic process. Zdravkovic investigated the effect of polysorbate 80 , a non-ionic surfactant commonly used in various formulations, on the solubilization of DEHP 
from PVC bags [50]. The presence of polysorbate 80, already in very low concentrations, caused DEHP to leach and become solubilized. Hanawa et al. looked at the effect of HCO-60, a polyoxyethylene castor oil derivative, on the release of DEHP from PVC tubing [51]. Leaching of DEHP into the solution increased with increasing HCO-60 amounts but the formation of micelles did not affect the amount leached. This indicates that the release of DEHP from the PVC was not due to DEHP dissolution in the micelles, but rather due to interactions between DEHP and HCO-60.

\section{Some consequences of the physical properties of plasticisers inter- actions with amphiphiles}

Environmental and biological effects are governed by physiochemical properties of the involved molecules. However, the relevant interactions can be very specific and complicated. In many cases, it is not clear what causes certain biological effects. Identifying the specific interactions and properties, and their consequences, is not trivial. Some key biological and environmental effects of plasticisers that are broadly related to their physical properties are described below.

\subsection{Biological effects}

The biological effects of phthalate-based plasticisers have been a popular field of study for quite some time. Phthalates have not been shown to possess any acute toxicity and although several studies have shown adverse toxicological effects in animal studies, it is unclear how well this applies to humans [52]. It is generally held that DEHP, one of the more common phthalates, negatively affects reproduction in humans and it is well known that it disrupts the endocrine system $[53,54]$. DEHP has also been shown to increase lipid peroxidation in red blood cells and it is thought that this could be due to replacement of vitamin E, which is an antioxidant, in membranes [55]. Similarly, the presence of DBP has been shown induce similar effects, reproductive toxicity and oxidative stress, in rats [56]. Conversely, DINCH, one of the suggested replacements for phthalates, did not induce any systemic toxicity in rats [57]. Thomas et al. [ 58] have published a comprehensive review of the biological effects of DEHP and other phthalic esters and the general aspects of this topic will not be described here.

\subsection{Blood storage}

Blood bags are typically made out of PVC because of its ideal properties for blood storage (gas permeable, heat resistant and appropriate tensile strength). However, in order to achieve these ideal properties, plasticisers are added to reduce the rigidity of the material. The most commonly used plasticiser for this purpose is DEHP and it is added in amounts up to $40 \%$ of the total mass. PVC does not retain DEHP well which results in significant leaching into the stored blood. As previously discussed, the solubility of DEHP in water is very low, although it is higher in blood. It is clear that DEHP in blood does not generally exist as free molecules but is either bound to proteins or it is partitioned into membranes that help solubilise them. This is what is expected considering its previously discussed physical properties. There are various reports as to what is the concentration of DEHP in stored blood: Holme [59] reported concentrations of 20-60 $\mu \mathrm{g} \mathrm{mL}^{-1}$, Rael et al. [60] reported $10-20 \mu \mathrm{g} \mathrm{mL}^{-1}$ while AuBuchon et al. reported concentrations up to $150 \mu \mathrm{g} \mathrm{mL}^{-1}$ after 35 days of storage [9]. Holme reports that $10 \%$ of the DEHP enters the blood cell membranes and AuBuchon et al. describe similar amounts with 5-10\% going into the blood cells. With a phospholipid content of 3-4 mg mL ${ }^{-1}$, the relative amount of DEHP that enters membranes is significant compared to the lipid content [61]. Despite its harmful nature, as discussed in the previous section, the presence of DEHP have a stabilising effect on the blood cells it is present in. During storage, red blood cells suffer morphological deterioration as well as loss of lipids through vesicle formation, but the presence of DEHP reduces deformation and haemolysis and improves blood cell morphology during storage [11]. The amount of free haemoglobin is one indicator of damage to the blood cells. Estep et al. [6] investigated the effect of DEHP in mixtures of blood and emulsifier and found a two-fold decrease in free haemoglobin when DEHP was introduced, which corresponds to a significant increase in intact blood cells. Similarly, a patent by Estep describes how the morphology of blood cells was maintained for longer when more DEHP was added, up to a stated limit [62]. Concentrations of DEHP up to $600 \mu \mathrm{g} \mathrm{mL}^{-1}$ had a positive effect on the quality of stored blood, amounts beyond that caused increased haemolysis and decreased resistance to morphological changes. These results are illustrated in Fig. 9.

Much of the research surrounding phthalates, and especially DEHP, concerns the challenges in finding a suitable replacement. For DEHP this need is complicated further by the identified beneficial effects it has on the viable lifetime of stored blood. However, interactions between blood cells and non-polar molecules are not limited to plasticisers. Identifying other types of molecules that have a similar role to DEHP is not only a necessary step to replacing it, but also helps provide understanding as to what causes the beneficial interaction with blood cells. Roth and Seeman reported that several lipid soluble anaesthetics also influence blood cells by reducing haemolysis [63]. In their reported data, there are trends that indicate that molecules that are more non-polar have greater effect on blood cells than hydrophilic

(a)

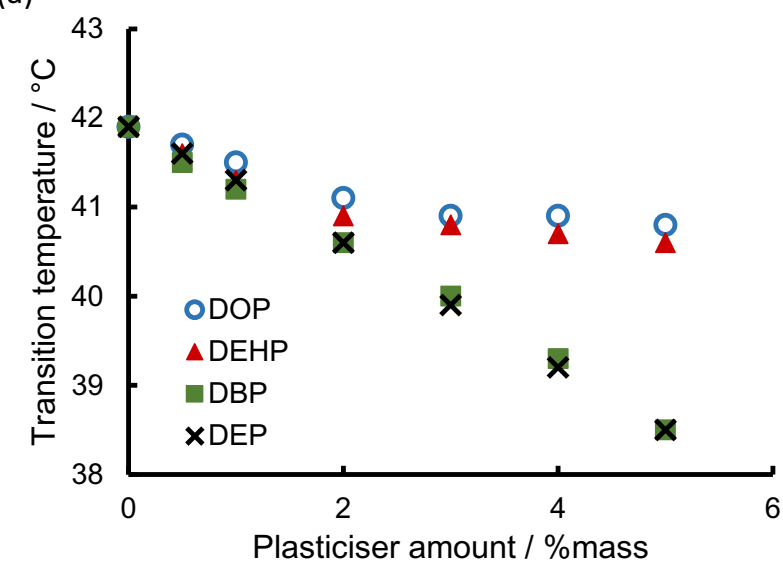

(b)

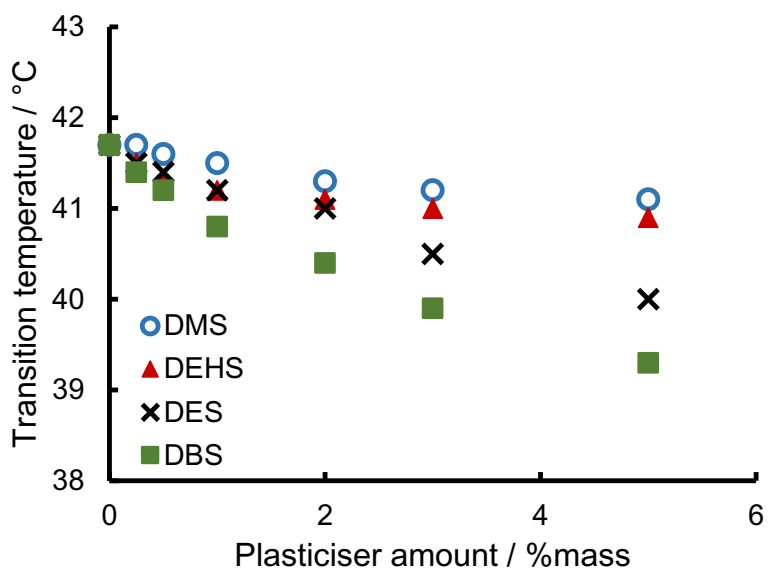

Fig. 8. Change of transition temperatures with amount of plasticiser for dipalmitoyl phosphatidylcholine (DPPC) vesicles containing (a) phthalate plasticisers diethyl phthalate (DEP), dibutyl phthalate (DBP), diethylhexyl phthalate (DEHP) and di- $n$-octyl phthalate (DOP) and (b) sebacate plasticisers: dimethyl sebacate (DMS), diethyl sebacate (DES), dibutyl sebacate (DBS) and diethylhexyl sebacate (DEHS). Data from Bonora et al. [42,43]. 
molecules. In a series of n-alcohols from ethanol to n-undecanol, the number of molecules needed to achieve a $50 \%$ reduction in haemolysis was reduced roughly five-fold for every carbon added beyond npropanol. Decreasing polarity corresponds to increased partitioning into non-polar solvents/structures like the cell membrane of blood cells, where the presence of such molecules alters the membrane properties by increasing the area per lipid molecule.

Melzak et al. found more specifically that the presence of DEHP in blood cells promotes a relative increase in the area of the inner leaflet relative to the outer leaflet of the membrane in red blood cells [64]. This induces a change in cell shape that counteracts the shape changes that are associated with long-term storage. Their results indicate that DEHP changes the distribution of phosphatidylserine, a lipid that is more common in the inner leaflet. These authors propose that the most likely reason for DEHP inducing lipid flip-flop is because it causes the phosphatidylserine lipids to move from the inner to the outer leaflet of a bilayer.

\subsection{Plasticisers in the environment}

Due to the very wide use of PVC based materials, significant amounts of plasticiser have leached into the environment. As phthalates are historically by far the most widely used plasticisers, this concern relates mostly to phthalates. Newly produced DEHP free medical devices have been found to contain amounts of DEHP that are higher than recommended, and this even applied to nominally DEHP-free products [65]. The likely cause for this observation is the high amount of DEHP in the

(a)

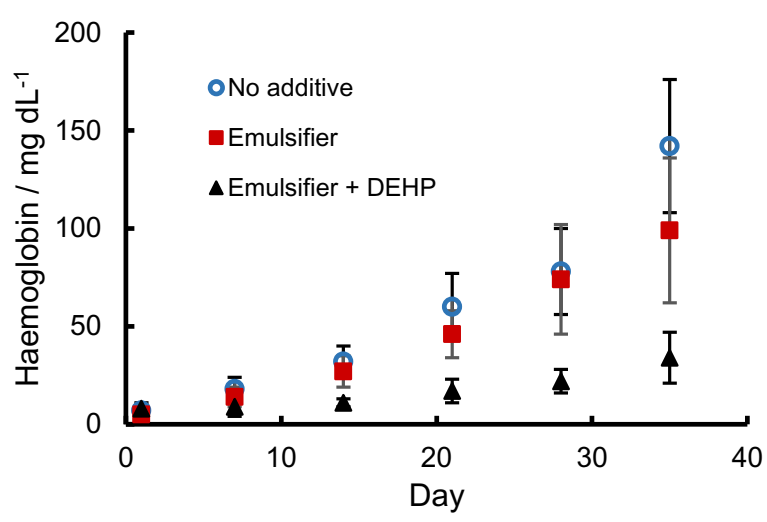

(b)

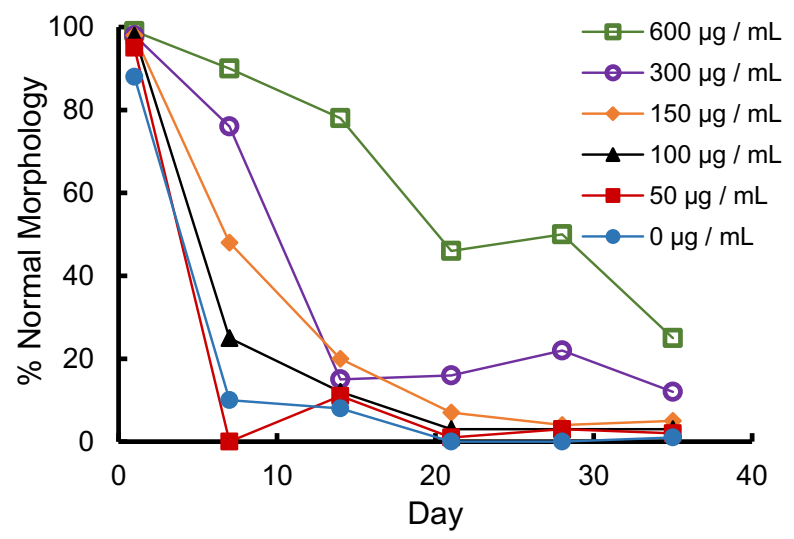

Fig. 9. (a) Free haemoglobin detected in blood as a function of time for pure blood, blood with emulsifier and blood with emulsifier and DEHP as a function of time. Data from Estep et al. [6] (b) Percent of total red blood cells with a normal morphology as a function of time for different concentrations of added DEHP. Data from Table 1 of Estep [62]. environment, which makes exposure to DEHP inevitable. DEHP is found in soil, water and atmosphere meaning that animals and plants alike receive almost constant exposure to it [66]. Incorporation of DEHP occurs through several pathways with ingestion, inhalation, injection and absorption through skin contact identified as viable routes [67]. In aquatic environments phthalates may be adsorbed to particulate matter and branching of the ester chains has been shown to increase adsorption $[68,69]$. Shorter chain phthalate esters have been found in the surface microlayer of lakes, while long chain phthalates such as DOP and DEHP were not found [70]. In the atmosphere, phthalates are found both deposited on aerosols and as free molecules and it has been reported that the presence of DEHP in seawater could affect aerosol lifetime [71].

\section{Conclusions}

This review brings together reports on the interactions of amphiphiles with plasticisers that are widely used. Interactions of these materials are very important as many of the plasticisers, particularly phthalate esters, have been implicated as hazardous to health or to be problematic in the environment. As the routes by which the plasticisers will be incorporated into cells depend on their interaction with for example lipids, the data and understanding of these mixtures is very important. Experimental studies on these systems rely on basic data such as for solubility, partition coefficients and vapour pressure. Predictive models are useful, particularly for systems where this basic experimental data is missing. It is evident that many plasticisers, that are meant to replace phthalates, have yet not been studied sufficiently. The use of various predictive tools therefore provides a way to obtain some insight into the behaviour of the molecules in various situations, even if they only provide some approximate estimates. The predictive tools that have been identified in this review show generally good agreement with experimental data, and at the very least correctly predict trends that appear in various series of molecular structures. Data on the solubility of high molecular weight diesters had a high variance, especially from older publications. This highlights some of the problems with accurately determining the solubility of certain compounds. It' has been highlighted that the standard 'shake flask method' used to determine solubility can result in suspensions or emulsions forming which leads to overestimation of the solubility [2]. As an alternative the 'slow stir' method seems to produce more reliable and reproducible results [20].

One specific conclusion of this study is that although one might expect the very low aqueous solubility and vapour pressure of many plasticisers to effectively limit exposure, the extensive binding and association with lipids and plasma proteins apparently provides very efficient transport. The very high initial concentrations of plasticisers that are necessary to obtain desirable properties of plastics, particularly polyvinyl chloride imply that large amounts can accumulate particularly in lipophilic environments [72]. This accumulation provides special concerns as regards toxicity.

From the review of previous work in the literature, it is apparent that there are many more studies on the older plasticisers, particularly of the now deprecated DEHP. While understanding the beneficial properties of this compound on blood storage is important, it is also useful to establish reliable data on the possible alternatives that are not yet in widespread use both as regards physico-chemical properties and eventual effects on the environment or implications for health. The comparison of measured data for e.g. solubility with estimates from available software or simple model calculations shows reasonable correlations but indicates that experimental studies cannot entirely be replaced.

Replacement of conventional plasticisers can be envisaged but it is particularly interesting to explore novel alternatives that might provide very little material that could leach to the environment. Several groups [73-75] have recently been exploring covalently bound alternatives with plasticizing moieties that are included as part of a copolymer structure for materials like PVC. These developments would reduce exposure 
to chemicals that have been identified as harmful. The challenge that has been mentioned above that is related specifically to storage of donated blood remains, and its resolution requires a specific understanding as to how a compound such as DEHP reduces haemolysis and the development of non-toxic replacements or finding other means to extend the viable storage-time of blood and blood cells.

At present, however, much of the effort towards replacement of plasticisers is directed towards studies of esters of alternative polyvalent organic acids such as citric acid and trimellitic acid. Some practical studies $[25,76]$ have indicated that less tri-2-ethylhexyl trimellitate (TOTM) is leached into biologically relevant fluids than DEHP but further studies of physical properties and any possible health effects of these materials are desirable. More investigation of both these classes of materials is recommended. These experiments and the other studies that have been described above suggest that the eventual fate of plasticisers in the body or more widely in the environment can depend sensitively on many factors such as additional components in water or aqueous solution such as amphiphiles, proteins or particles. For these reasons wider determination of data about interactions is desirable.

\section{Declaration of Competing Interest}

The authors declare that they have no known competing financial interests or personal relationships that could have appeared to influence the work reported in this paper.

\section{Acknowledgements}

We are grateful to Swedish Strategic Research Foundation (SSF) for partial funding of this work within the framework of studies within the Swedish Neutron School, SwedNESS, grant number GSn15-0008.

\section{Appendix A. Supplementary data}

Supplementary data to this article can be found online at https://doi. org/10.1016/j.cis.2020.102109.

\section{References}

[1] Warner GR, Flaws JA, Bisphenol A. Phthalates: how environmental chemicals are reshaping toxicology. Toxicol Sci 2018;166(2):246-9.

[2] Staples CA, Peterson DR, Parkerton TF, Adams WJ. The environmental fate of phthalate esters: a literature review. Chemosphere 1997;35:667-749.

[3] Ventrice P, Ventrice D, Russo E, De Sarro G. Phthalates: European regulation, chemistry, pharmacokinetic and related toxicity. Environ Toxicol Pharmacol 2013;36: 88-96.

[4] Faessler D, McCombie G, Biedermann M, Felder F, Subotic U. Leaching of plasticizers from polyvinylchloride perfusion lines by different lipid emulsions for premature infants under clinical conditions. Int J Pharm 2017;520:119-25.

[5] Malarvannan G, Onghena M, Verstraete S, van Puffelen E, Jacobs A, Vanhorebeek I, et al. 'phthalate and alternative plasticizers in indwelling medical devices in pediatric intensive care units. J Hazard Mater 2019;363:64-72.

[6] Estep TN, Pedersen RA, Miller TJ, Stupar KR. Characterization of erythrocyte quality during the refrigerated storage of whole blood containing di-(2-ethylhexyl) phthalate. Blood 1984;64:1270-6.

[7] Horowitz B, Stryker MH, Waldman AA, Woods KR, Gass JD, Drago J. Stabilization of red blood cells by the plasticizer, diethylhexylphthalate. Vox Sang 1985;48(3): $150-5$.

[8] Labow RS, Card RT, Rock G. The effect of the plasticizer di(2-ethylhexyl)phthalate on red cell deformability. Blood 1987;70(1):319-23.

[9] AuBuchon JP, Estep TN, Davey RJ. The effect of the plasticizer di-2-ethylhexyl phthalate on the survival of stored RBCs. Blood 1988;71:448-52.

[10] Kanias T, Lanteri M, Derek S, Busch M, Gladwin MT. Red blood cell storage in Pediatric transfer bags is correlated with increased levels of hemolysis and altered osmotic fragility. Blood 2013;122:2403.

[11] Bicalho B, Serrano K, dos Santos Pereira A, Devine DV, Acker JP. Blood bag plasticizers influence red blood cell vesiculation rate without altering the lipid composition of the vesicles. Transfus Med Hemother 2016;43:19-26.

[12] Regulation. 2017/745 of the European parliament and of the council of 5 April; 2017.

[13] Somheil T. Study: global PVC demand to grow 3.2\% annually through 2021. Plastics Today 25 August 2014. https://www.plasticstoday.com/content/study-global-pvcdemand-grow-32-annually-through-2021/17670326321043.
[14] Peakall DB. Phthalate esters: occurrence and biological effects. In: Gunther FA, editor. Residue reviews residues of pesticides and other contaminants in the total environment. Springer-Verlag; 1975.

[15] Bui TT, Giovanoulis G, Palm Cousins A, Magnér J, Cousins IT, de Wit CA. Human exposure, hazard and risk of alternative plasticizers to phthalate esters. Sci Total Environ 2016;541:451-67.

[16] Wypych A. Databook of plasticizers. . 2nd ed.ChemTec Publishing; 2017; 685.

[17] Góral M, Shaw DG, Mączyński A, Wiśniewska-Gocłowska B. IUPAC-NIST solubility data series. 88. Esters with water-revised and updated. Part 4. $C_{10}$ to $C_{32}$ esters. J Phys Chem Ref Data 2010;39:033107.

[18] US EPA. Estimation Programs Interface EPISuite ${ }^{\mathrm{TM}}$ for Microsoft ${ }^{\circledR}$ Windows, $v$ 4.11. Washington, DC, USA: United States Environmental Protection Agency; 2019.

[19] Karickhoff SW, McDaniel VK, Melton C, Vellino AN, Nute DE, Carreira LA. Predicting chemical reactivity by computer. Environ Toxicol Chem 1991;10:1405-16.

[20] Letinski DJ, Connelly Jr MJ, Peterson DR, Parkerton TF. Slow-stir water solubility measurements of selected alcohols and diesters. Chemosphere 2002; 48:257-65.

[21] Howard PH, Banerjee S, Robillard KH. Measurement of water solubilities, octanol/ water partition coefficients and vapor pressures of commercial phthalate esters. Environ Toxicol Chem 1985;4:653-61.

[22] Ellington JJ. Octanol/water partition coefficients and water solubilities of phthalate esters. J Chem Eng Data 1999;44:1414-8.

[23] Cousins I, Mackay D. Correlating the physical-chemical properties of phthalate esters using the 'three solubility' approach. Chemosphere 2000;41:1389-99.

[24] Ishak H, Stephan J, Karam R, Goutadier C, Mokbel I, Saliba C, et al. Aqueous solubility, vapor pressure, and octanol-water coefficient of two phthalate isomers dibutyl phthalate and diisobutyl phthalate contaminants of recycled food packages. Fluid Phase Equilibria 2016:427:362-70.

[25] Eckert E, Münch F, Göen T, Purbojo A, Müller J, Cesnjevar R. Comparative study on the migration of di-2-ethylhexyl phthalate (DEHP) and tri-2-ethylhexyl trimellitate (TOTM) into blood from PVC tubing material of a heart-lung machine. Chemosphere 2016;145:10-6.

[26] Cevc G, Berts I, Fischer SF, Rädler JO, Nickel B. Nanostructures in n-octanol equilibrated with additives and/or water. Langmuir 2018;34:6285-95.

[27] Acree W, Chickos JS. Phase transition enthalpy measurements of organic and organometallic compounds. Sublimation, vaporization and fusion enthalpies from 1880 to 2010. J Phys Chem Ref Data 2010;39:043101.

[28] Acree W, Chickos JS. Phase transition enthalpy measurements of organic and organometallic compounds and ionic liquids. Sublimation, vaporization, and fusion enthalpies from 1880 to 2015. Part 2. C11-C192'. J Phys Chem Ref Data 2017; 46:013104.

[29] Thomsen M, Carlsen L. Phthalater i Miljøet. Opløselighed, sorption og transport Technical report 249. Roskilde, Denmark: National Environmental Research Institute; 1998.

[30] Gobble C, Chickos JS. A comparison of results by correlation gas chromatography with another gas chromatographic retention time technique. The effects of retention time coincidence on vaporization enthalpy and vapor pressure. J Chem Eng Data 2015;609:2739-48.

[31] Aveyard R, Binks BP, Fletcher PDI, Kingston PA, Pitt AR. Surface chemistry and microemulsion formation in systems containing dialkylphthalate esters as oils. J Chem Soc Faraday Trans 1994;90:2743-51.

[32] Ricci E, Sangiorgi R, Passerone A. Density and surface tension of dioctylphthalate, silicone oil and their solutions. Surf Coat Technol 1986;28:215-23.

[33] Caetano FJP, Fareleira JMNA, Fernandes AC, Oliveira CMBP, Serro AP, Simões de Almeida IM, et al. Diisodecylphthalate (DIDP) - a potential standard of moderate viscosity: surface tension measurements and water content effect on viscosity measurements. Fluid Phase Equilibria 2006;245:1-5.

[34] Kalantarian A, Saad SMI, Neumann AW. Accuracy of surface tension measurement from drop shapes: the role of image analysis. Adv Colloid Interface Sci 2013;199200:15-22.

[35] Kauffman GW, Jurs PC. Prediction of surface tension, viscosity, and thermal conductivity for common organic solvents using quantitative structure-property relationships. J Chem Inf Comput Sci 2001:41:408-18.

[36] Goossens S, Seveno D, Rioboo R, Vaillant A, Conti J, De Coninck J. Can we predict the spreading of a two-liquid system from the spreading of the corresponding liquid/air systems? Langmuir 2011;27:9866-72.

[37] Diogo JCF, Avelino HMNT, Caetano FJP, Fareleira JMNA, Wakeham WA. Tris(2 ethylhexyl) trimellitate (TOTM) as a potential industrial reference fluid for viscosity at high temperatures and high pressures: new viscosity, density and surface tension measurements. Fluid Phase Equilibria 2016;418:192-7.

[38] Wypych A. Databook of plasticizers. 2nd ed. ChemTec Publishing; 2017; 206.

[39] Thomsen M, Carlsen L, Hvidt S. Solubilities and surface activities of phthalates investigated by surface tension measurements. Environ Toxicol Chem 2001;20:127-32.

[40] E. Gustafsson et al. [in preparation].

[41] Li S, Du L, Zhang Q, Wang W. Stabilizing mixed fatty acid and phthalate ester monolayer on artificial seawater. Environ Pollut 2018;242:626-33.

[42] Bonora S, Fini G, Piccirilli B. DSC study on the interaction between bis-2-(ethylhexyl) phthalate and other o-phthalic acid esters and dipalmitoyl phosphatidylcholine liposomes. J Therm Anal Cal 2000;61:731-43.

[43] Bonora S, Ercoli L, Torreggiani A, Fini G. Influence of sebacate plasticizers on the thermal behaviour of dipalmitoylphosphatidylcholine liposomes. Thermochim Acta 2002;385:51-61.

[44] Loff S, Subotic U, Reinicke F, Wischmann H, Brade J. Extraction of di-ethylhexylphthalate from perfusion lines of various material, length and brand by lipid emulsions. J Pediatr Gastroenterol Nutr 2004;39:341-5. 
[45] Münch F, Höllerer C, Klapproth A, Eckert E, Rüffer A, Cesnjevar R, et al. Effect of phospholipid coating on the migration of plasticizers from PVC tubes. Chemosphere 2018;202:742-9.

[46] Nouman M, Saunier J, Jubeli E, Yagoubi N. Additive blooming in polymer materials: consequences in the pharmaceutical and medical field. Polym Degrad Stab 2017; 143:239-52

[47] Marcilla A, Garcia S, Garcia-Quesada JC. Migrability of PVC plasticizers. Polymer Testing 2008;27:221-33.

[48] Waters LJ, Leharne SA, Mitchell JC, Hanrahan JP. Determination of micelle/water partition coefficients and associated thermodynamic data for dialkyl phthalate esters. Therm Anal Cal 2007;90:283-8.

[49] Waters LJ, Leharne SA, Mitchell JC. Saturation determination of micellar systems using isothermal titration calorimetry. J Therm Anal Cal 2005;80:43-7.

[50] Zdravkovic SA. Comparison of the solubilization properties of polysorbate 80 and isopropanol/water solvent systems for organic compounds extracted from three pharmaceutical packaging configurations. Eur J Pharm Sci 2016;93:475-83.

[51] Hanawa T, Endoh N, Kazuno F, Suzuki M, Kobayashi D, Tanaka M, et al. Investigation of the release behaviour of diethylhexyl phthalate from polyvinyl chloride tubing for intravenous administration based on HCO60. Int J Pharm 2003;267:141-9.

[52] Shea KM. Pediatric exposure and potential toxicity of phthalate plasticizers - technical report. Am Acad Pediatr 2003;111:1467-74.

[53] Center for the Evaluation of Risks to Human Reproduction NTP-CERHR. Monograph on the potential human reproductive and developmental effects of di(2-ethylhexyl) phthalate (DEHP) NIH publication no 06-4476; 2006.

[54] Latini G, Verrotti A, De Felice C. Di-2-ethylhexyl phthalate and endocrine disruption: a review. Curr Drug Targets 2004;4:37-40.

[55] Devi KVD, Kumar VM, Arun P, Santhosh A, Nair KGP, Lakshmi LR, et al. Increased lipid peroxidation of erythtrocytes in blood stored in polyvinyl chloride blood storage bags plasticized with di-(2-ethylhexyl)phthalate and effect of antioxidants. Vox Sang 1998;75:198-204.

[56] Aly HAA, Hassan MH, El-Beshbishy HA, Alahdal AM, Osman A-MM. Dibutyl phthalate induces oxidative stress and impairs spermatogenesis in adult rats. Toxicol Ind Health 2016;32:1467-77.

[57] David RM, White RD, Larson MJ, Herman JK, Otter R. Toxicity of Hexamoll DINCH following intravenous administration. Toxicol Lett 2015;238:100-9.

[58] Thomas JA, Thomas MJ, Gangolli SD. Biological effects of di-(2-ethylhexyl) phthalate and other phthalic acid esters. Crit Rev Toxicol 1984;13(4):283-317.

[59] Holme S. Current issues related to the quality of stored RBCs. Transfus Apher Sci 2005;33:55-61.

[60] Rael LT, Bar-Or R, Ambruso DR, Mains CW, Slone DS, Craun ML, et al. Phthalate esters used as plasticizers in packed red blood cell storage bags may lead to progressive toxin exposure and the release of pro-inflammatory cytokines. Oxid Med Cell Longev 2009;2:166-71.
[61] Farquhar JW, Ahrens EH. Effects of dietary fats on human erythrocyte fatty acid patterns. J Clin Invest 1963;42:675-85.

[62] T. N. Estep, Additive solution and method for preserving normal red cell morphology in whole blood during storage, United States Patent 4,386,069 May 31, 1983.

[63] Roth S, Seeman P. All lipid soluble anaesthetics protect red cells. Nat New Biol 1971; 231:284-5.

[64] Melzak KA, Uhlig S, Krischhöfer F, Brenner-Weiss G, Bieback K. The blood bag plasticizer Di-2-Ethylhexylphthalate causes red blood cells to form Stomatocytes, possibly by inducing lipid Flip-flop. Transfus Med Hemother 2018;45:413-22.

[65] Genay S, Luciani C, Décaudin B, Kambia N, Dine T, Azaroual N, et al. Experimental study on infusion devices containing polyvinyl chloride: to what extent are they di (2-ethylhexyl)phthalate-free? Int J Pharm 2011;412:47-51.

[66] Wormuth M, Scheringer M, Vollenweider M, Hungerbühler K. What are the sources of exposure to eight frequently used phthalic acid esters in Europeans? Risk Anal 2006;26:803-24.

[67] Schettler T. Human exposure to phthalates via consumer products. Int J Androl 2006;29:134-9.

[68] Zeng F, Wen J, Cui K, Wu L, Liu M, Li Y, et al. Seasonal distribution of phthalate esters in surface water of urban lakes in the subtropical city, Guangzhou, China. J Hazard Mater 2009;169:719-25.

[69] Preston MR, Al-Omran LA. Phthalate ester speciation in estuarine water, suspended particulates and sediments. Environ Pollut 1989;62:183-93.

[70] Wu M, Yang X, Xu G, Que C, Ma S, Tang L. Semivolatile organic compounds in surface microlayer and subsurface water of Dianshan lake, Shanghai, China: implications for accumulation and interrelationship. Environ Sci Pollut Res 2017;24:6572-80.

[71] Thurén A, Larsson P. Phthalate esters in the Swedish atmosphere. Envrion Sci Technol 1990;24:554-9.

[72] Jaeger RJ, Rubin RJ. Migration of a phthalate ester plasticizer from polyvinyl chloride blood bags into stored human blood and its localization in human tissues. N Engl J Med 1972;287:1114-8.

[73] Navarro R, Pérez Perrino M, García C, Elvira C, Gallardo A, Reinecke H. Highly flexible PVC materials without plasticizer migration as obtained by efficient one-pot procedure using trichlorotriazine chemistry. Macromolecules 2016;49:2224-7.

[74] Earla A, Li L, Costanzo P, Braslau R. Phthalate plasticizers covalently linked to PVC via copper-free or copper catalyzed azide-alkyne cycloadditions. Polymer 2017; 109:1-12.

[75] Higa CM, Tek AT, Wojtecki RJ, Braslau R. Nonmigratory internal plasticization of poly (vinyl chloride) via pendant Triazoles bearing alkyl or polyether esters. J Polym Sci A Polym Chem 2018;56:2397-411.

[76] Kambia K, Dine T, Azar R, Gressier B, Luyckx M, Brunet C. Comparative study of the leachability of di(2-ethylhexyl) phthalate and tri(2-ethylhexyl) trimellitate from haemodialysis tubing. Int J Pharm 2001;229:139-46. 